\title{
EL QUIASMO COMO DESVELO DE LA OTREDAD: PROYECCIONES ESPECULARES Y DISTORSIÓN DE LA MONSTRUOSIDAD EN LOS OTROS (2001), DE ALEJANDRO AMENÁBAR
}

\section{Julio Ángel Olivares Merino}

Universidad de Jaén

\begin{abstract}
Pivoting around the epicentric character of Grace Stewart, our approach intends to cast a light on the imagery of phantasmagoria, violence and manipulation emerging from the univocal point of view in The Others so as to underline the keys of a necessary deconstruction of the dark mother's central voice in the discourse. Several resisting and peripheral readings as well as figurative marks - the chiasmus being a constant - evince the mother's role as a fallible and schizoid antagonist.
\end{abstract}

Keywords: chiasmus, ghosts, the others, dark mother, Alejandro Amenábar, point of view

\section{Resumen}

Pivotando en torno al personaje epicéntrico de Grace Stewart, nuestra aproximación pretende sumergirse en el imaginario de fantasmagoría, violentación y monopolización del punto de vista unívoco en Los otros a fin de subrayar las claves de una necesaria deconstrucción de la voz y el discurso de la madre oscura. Las múltiples lecturas periféricas y resistentes, además de ciertos indicios figurativos — con el quiasmo como constante - refrendan el papel de aquella como antagonista falible y esquizoide.

Palabras clave: quiasmo, fantasmas, los otros, madre oscura, Alejandro Amenábar, punto de vista 


\section{Umbral, laberinto y llaves: sobre paraísos e infiernos}

Heredera de Otra vuelta de tuerca (1898), de Henry James, epítome y sublimación literaria de la ambigüedad 1 como recurso creativo y garante multiplicador del potencial significativo del texto, Los otros (2001) se erige en discurso que problematiza la interpretación unívoca de los hechos, sustancia la relativa y movediza esencia de categorías tales como lo real, lo irreal, lo familiar y lo extraño, e impele a la deconstrucción del único punto de vista, no fiable, dentro de la historia. La polifonía y la progresiva legitimación de las lecturas resistentes a la monopolización ejercida por la figura omnipresente y aparentemente omnipotente de la madre, Grace Stewart, plantean una gradual democratización de la verdad, cuestionando el discurso del matriarcado y redefiniendo los referentes de la certidumbre en un texto enclaustrado y confinado física y psicológicamente a unos horizontes de expectativa tan relativos como represivos.

Aparentemente bella, con luz propia, si bien oscura y manipuladora en esencia, Grace representa en el metraje de Amenábar esa dualidad que suele caracterizar a los personajes femeninos dentro de su producción fílmica. Proyectada sobre un imaginario de consunción, abandono, ausencia patriarcal, desemantización y cuestionamiento constante de la realidad a través de la disolución de las fronteras entre lo tangible y lo metafísico, el personaje se vincula a la imagen de una progenitora abnegada y valiente en su anhelo de proteger a sus hijos. Así, investida de las trazas propias del ángel de la casa victoriano y la heroína gótica, Grace se afana en preservar la seguridad de estos a toda costa, delimitando la frontera entre la intimidad y domesticidad asociadas a la unidad familiar frente a la contaminación externa e invasiva de lo siniestro.2 Al tiempo, y en el extremo opuesto, se plasma, amenazadoramente, como dama oscura de rectitud déspota, enlutada, 3 símbolo de la tragedia, mensajera y ejecutora implacable de la muerte. Su caracterización en el film subraya esa efigie, a la vez, autoritaria — casi siempre estilizada y seria, como madrastra de cuento, con atavíos de hombros marcados y pronunciados - y discreta, elegante,

\footnotetext{
1 Nicole Burkholder-Mosco y Wendy Carse hablan de liminalidad (201).

${ }^{2}$ En el género gótico, la amenaza exterior como acecho en el perímetro asegurado de la domesticidad suele representar el conflicto entre el individuo y la sociedad. Extrapolando esta idea al gótico femenino, Ellen Moers sostiene que la casa es correlato del cuerpo desposeído y enajenado de la feminidad.

${ }_{3}$ Como los sirvientes, esos otros símbolos de la desventura, Grace suele vestir de oscuro - la gama de colores de sus atavíos va del negro al púrpura, incluyendo la melancolía del azul—, lo cual multiplica el contraste con la ígnea palidez de su rostro y hace que, difuminada su silueta en la oscuridad reinante, focalicemos aun más las inflexiones de su expresividad —ayudados por la claridad del quinqué-, esa mutabilidad drástica entre ternura, mueca doliente y soslayo empavorecido.
} 
comedida, con trajes abotonados hasta el cuello, salvo el camisón - aun sobrio- que viste en la secuencia del reencuentro con Charles, su esposo, en el dormitorio conyugal, sin obviar su bata color púrpura con camisa blanca, que apenas si le permite lucir escote.

El personaje de Grace, como la historia, resulta tan complejo como enigmático y desconcertante, tan resuelto como desorientado o desposeído de la razón, tan estático como dinámico. Provoca la identificación y empatía del espectador ya desde la génesis del relato, impeliéndonos a interpretar los hechos a partir de su categorización de la realidad, solipsista4 y ciega, refrendada en el enclaustramiento y la ausencia de luzs, además de en la multiplicación de textos y niveles narrativos o ecos que espejean y justifican su visión. Con todo, Grace queda desplazada, súbitamente, al papel de antagonista, cercana la conclusión, ya en el último suspiro de la diégesis, justo cuando recupera de nuevo un cetro maternal de dominio y poder ciertamente iluso, más distópico que utópico. De hecho, no es sino hasta esa parte final del film cuando, a través de un giro narrativo que rompe nuestras expectativas, 6 somos conscientes de que toda realidad tangible e inmediata, toda asunción e interpretación aparentemente sólida y construida previamente a través de los ojos de Grace, es necesariamente cuestionable, como falacia impuesta, y oculta - en un proceso sistemático de negación (Hock 149) — una verdad a modo de reflejo simétrico invertido,7 un quiasmo revelador8 que invita a repensar en retrospectiva cada hecho, cada aseveración y comportamiento normalizados a partir del enjuiciamiento de la

\footnotetext{
${ }^{4} \mathrm{Su}$ interpretación de los hechos difiere de las lecturas resistentes a las que nos referiremos en nuestra aproximación, manifestándose una tendencia a la soledad y alienación progresiva. Afirma Grace, ante su confidente, la señora Mills: "Empiezo a sentirme totalmente aislada del mundo. Y esta niebla no ayuda" (Amenábar 66).

5 La atmósfera enrarecida, macabra, gélida y fantasmática, además de la impecable puesta en escena, junto con la cartesiana composición de planos, con evidente influencia expresionista, son pilares esenciales en el film.

6 Ese "twist" narrativo final es lo que Seth Friedman denomina "changeover", una constante en la corriente que el crítico denomina "misdirection films". Véase el estudio "Narrative Structure in The Sixth Sense: A New Twist in 'Twist Movies'?", de Erlend Lavik, para una aproximación al punto de inflexión como estrategia narrativa.

7 Considérese el encuadre de contextualización — "establishing shot" (imagen 1) - de los exteriores de la mansión que representa la proyección especular de la casa en el estanque, sugiriendo otros planos alternativos y latentes al universo plasmado en superficie. Resultan igualmente significativos a la hora de insinuar la presencia de lo velado aquellos enmarques que focalizan con nitidez la figura de Grace y revelan formas indistintas desenfocadas en un segundo plano.

8 En consonancia con esta figura retórica, la construcción del film consiste en una repetición especular - trasuntos y reduplicaciones constantes-, además de la significativa inversión final de los elementales que se presentan como foco real y legitimado durante la génesis y el desarrollo con respecto a los supuestos simulacros o representaciones de otredad. Estos ocupan el papel de aquellos — en el epicentro del discurso - y aquellos, el de estos — desplazados a la dimensión de lo fantasmático.
} 
madre durante el transcurso de la historia. Es evidente que los indicios que definen a Grace como punto de vista no fiable son gradual y crecientemente más constatables en el discurso, empezando ya por el grito y desequilibrio del primer plano de su rostro - focalización diagonal — con los que se nos presenta al personaje tras el prólogo (imagen 2).

Así, el enclaustramiento y la insularidad multiplicados — casona aislada dentro del entorno de una isla, a su vez, apartada del mundo - 9 a los que se ve abocada la unidad familiar de Grace - resquebrajada e incompleta en ausencia del esposo, que marchó al frente y no ha regresado aún- son resultado, según refiere ella misma, del asedio del ejército alemán durante la Segunda Guerra Mundial. Sin presencia explícita del enemigo nazi —el film está ambientado justamente tras el final del citado conflicto-, la otredad invasiva se resitúa en "los otros", las presencias que, supuestamente, se han instalado en la casona con propósitos hostiles. La realidad, sin embargo, resulta ser otra muy diferente, como conocerá el espectador - y los propios personajes - justo en el punto climático de la narración, ya que el afán de sobreprotección de Grace con respecto a sus hijos, su obsesiva inclinación a hacerles cumplir escrupulosamente cada mandamiento religioso y a entender la realidad sólo y exclusivamente a partir de sus normas y opiniones la llevan a aislarlos del exterior, a oprimirlos y a arrebatarles, más allá de la libertad y su capacidad crítica, incluso la vida.10 De este modo, aquella que podría considerarse trasunto de la "final girl" (Clover 201) que logra sobrevivir a las contrafiguras en la historia, se convierte en la verdadera antagonista del relato.11

Más específicamente, y a diferencia del gótico tradicional, en el que la ausencia del referente femenino — maternal, para ser más precisos — subraya la inutilidad del patriarcado y el sistema falocéntrico — recuérdese esa ausencia de la madre en Frankenstein, el moderno Prometeo o en Jane Eyre, que deviene

\footnotetext{
${ }_{9}$ Se reproduce el arquetipo de la mansión victoriana habitada por fantasmas — propia de la "ghost story"-, heredera del "locus" de lo ominoso tematizado en los albores del género gótico.

10 Hock (144) asocia la espectralidad en el film a la psicopatía y al concepto freudiano de melancolía. Es este un estado que, a diferencia del luto, no permite al sujeto liberarse del objeto perdido - que, en este caso, no es la persona anhelada sino el sujeto que la anhela- para reconstruirse o regenerarse. La melancolía enajena y despersonaliza a Grace, la sume en un estado depresivo, llevándola a proyectar todo un imaginario y arquitectura siniestra y doliente a su alrededor, además de hacerla sentir inquina por sí misma y, en su caso extremo, al suicidio. 11 Según Tony Williams el monstruo en el género de terror fílmico se origina habitualmente dentro del seno familiar (15) y es, por ende, referente ligado al ámbito doméstico (Becker 4). Más específicamente, Sarah Arnold señala una corriente - lo que ella denomina "maternal horror cinema" - en la que, desmitificando el concepto de madre idealizada, destaca el arquetipo de "bad mother", aquella que obvia sus obligaciones como progenitora o, por el contrario, se excede patológicamente en las mismas (4), como es el caso que nos ocupa.
} 
desorientación e inestabilidad emocional y social-, es el vaciado del significante paternal el que provoca el desmoronamiento de toda la unidad familiar en Los otros.12 Privada de tal referente, incapaz de gestionar la situación y asumir el control, la madre desata la tragedia, aunque, en su descargo, acusa a su esposo, de abandonar el hogar y descuidar sus obligaciones para marchar a combatir en una guerra ajena.13 A pesar de perseguir un propósito plausible, proteger a los suyos y delimitar un perímetro de seguridad en el espacio doméstico, Grace plantea una lid perpetua contra las circunstancias cuando, en realidad, ya ha perdido el principal combate, aquel que la enfrenta consigo misma. La responsabilidad asumida a solas, el apartamiento y la gradual enajenación —introspección nociva al no ser capaz de poner límites a su cegazón religiosa - la llevan a cometer el terrible infanticidio.14

Tres son, en concreto, los referentes simbólicos que representan y delatan la acción victimizadora de Grace en el film: el primero, el silencio que ella impone - Biblia en mano - como máxima mandataria en la casa y ostentadora de la única verdad que ha de imperar. Son su palabra y su interpretación de los hechos 15 las que los niños y sirvientes han de asumir y repetir como propias y

12 John Lewis estudia la película de Amenábar, además de El sexto sentido y The Ring como epítomes de la representación en el cine de terror contemporáneo hollywoodiense del empoderamiento fallido de aquella maternidad que no cuenta con el referente masculino, insistiendo en las graves consecuencias derivadas de una educación monoparental.

${ }^{13}$ Los referentes patriarcales o masculinos están minimizados, a la sombra de los personajes femeninos, entre los que se produce una pugna evidente por hacerse con el control de la situación. Además de la testimonial figura de Charles, en el trasunto de unidad familiar constituida por los sirvientes, el señor Tuttle apenas si interviene, dejando el protagonismo a la señora Mills. En la comitiva de "los otros", es la anciana la que dinamiza la acción, mientras que la familia de Víctor permanece a la expectativa. Finalmente, también es simple actante referido y ausente en escena el sacerdote del pueblo.

14 Para una aproximación al detalle al tema del infanticidio en el film de Amenábar, véase el estudio de Isabelle Torrance, "Retrospectively Medea: The Infanticidal Mother in Alejandro Amenábar's Film The Others".

15 Esta imposición del silencio — según Grace, no se da ruido alguno en la casa, es decir, interferencias de otras voces que generen un significante o significado alternativo, una polifonía desposeedora - se ve respaldada por una incomunicación absoluta con el exterior. No hay teléfono ni radio, aunque, como constataremos, el hermetismo del régimen autoritario representado por Grace se verá minado y resquebrajado por la invasión que llamará a su puerta - los sirvientes - y la que ya mora en el interior, el despecho de su propia hija y la invocación de la verdad durante la sesión de ouija. Son modos de actualización de un discurso aislado, anacrónico y no legitimado.

Al hilo del silencio, también la banda sonora de la película se caracteriza por la ausencia tensional de música. Amenábar crea expectación y suspense, además de sensación de vulnerabilidad y soledad, precisamente, a través del vacío melódico y la emersión puntual de instrumentación de cuerda. De esta forma, proyectados sobre un fondo sonoro neutro, los sollozos o resuellos de Grace y los niños resultan aún más dramáticos. Para un análisis exhaustivo de la apoyatura musical en Los otros, véase el estudio de Lloyd Whitesell, "Quieting the Ghosts in The Sixth Sense and The Others". 
objetivas. Valiéndose del ejercicio de la autoridad, el despotismo y la sobreprotección, Grace pretende instaurar, así, un automatismo servil, fundamentado también obsesivamente en el aleccionamiento religioso, 16 más que probablemente, debido a su necesidad de redimirse del pecado original que reprime y la lleva a nacer permanentemente del grito, tras cada ciclo de día en su ideación o ficcionalización de existencia. Así, Grace anula la asertividad, el posicionamiento crítico y la individuación de aquellos que están bajo su tutela amenazándoles con el castigo eterno, allá en el limbo, si no cumplen con lo dictado. Asevera la madre:17

En el centro de la Tierra. Donde hace mucho, mucho calor. Allá van los niños que dicen mentiras. Pero fijaos que no van por unos días, no. Se condenan para siempre, hasta la eternidad. Pensad en ello. Intentad imaginar la eternidad. Vamos, cerrad los ojos e imagináoslo ... Eso es la eternidad... para siempre... Dolor para siempre (Amenábar 38).

La lectura y repetición de textos ya constreñidos en su significado, sin margen de recreación, supone una evangelización y monopolización del comportamiento la parábola religiosa como referente que va calando en la memoria y se torna en parámetro ejemplar a partir de su interiorización-, además de garantizar la obediencia ciega, una recepción pasiva y, por ende, la subyugación a un credo supuestamente modélico (imagen 3).18 Así reza uno de los pasajes que el pequeño Nicholas ha de memorizar:

Todos vivimos en una casa en compañía de nuestra familia. Las principales habitaciones de la casa son: la cocina, el comedor, los dormitorios, el cuarto de aseo ... Las casas buenas tienen ventanas

\footnotetext{
${ }_{16}$ Casi inadvertido para el espectador, escrito sobre una pizarra que se ve fugazmente en una de las estancias de la casona, podemos leer: "Thank God for their growth in faith and love".

${ }_{17}$ Grace alecciona a sus hijos en los conceptos de "la mentira, el infierno o la culpa" (López 244). En aras de preservar un comportamiento acorde con los edictos religiosos —obediencia, en puridad, a sus mandamientos casi divinos dentro del microcosmos de la mansión-, la madre proyecta, dentro de su cosmogonía acomodaticia e impositiva, ese espacio metafísico amenazador. Es un infierno en el que ha de sufrir castigo y condena eterna todo niño que no se atenga al credo religioso. Curiosamente, como el espectador advertirá, Grace está describiendo la falta de luz y el averno a los que la madre condena a sus hijos. De hecho, la muerte por asfixia de los niños es ilustración metafórica de su opresión y victimización, hasta el punto de no dejarles espacio o libertad, ni siquiera para respirar. Esto se revela explícitamente en una de las reprimendas de Grace a Anne, en la que le ordena: "Deja de respirar así ... Deja... de respirar" (Amenábar 111), justamente la misma orden que traslada la hija a Nicholas, próxima la conclusión del film, cuando ambos se esconden en un armario: "Nicholas, deja de respirar así ¡Deja de respirar!” (Amenábar 155), demanda la niña a su hermano.

18 Entre otros, destacan los pasajes relativos a la expulsión del hombre del Edén —resulta especialmente significativo al ser el film una parábola sobre el fin de la inocencia y la consagración del pecado - y el sacrificio de Adán a manos de Abraham, indirectamente asociado al infanticidio.
} 
grandes y están muy limpias. La familia está formada por los padres, los hijos y los abuelos. Debemos ser obedientes y no debemos discutir (Amenábar 41-45).

Además, en relación con la sistemática imposición del silencio, subrayamos otro de los símbolos angulares en el film: la luz exterior, como metáfora de esa verdad que Grace pretende ocultar — sólo legitima la claridad artificial que ella porta, ese quinqué (imagen 4) que le permite ir abriendo puertas a su antojo (y de manera compulsiva casi) a través de la oscuridad acomodaticia-19 y de la que excluye a sus hijos — representación de la inocencia. Así, Grace identifica la luz de fuera como contrafigura que se ha de combatir, excusándose en la supuesta fotofobia - Xeroderma Pigmentosum - de los niños para confinarlos a los espacios indistintos de la ignorancia y la subyugación (imagen 5).20 Advierte Grace a la señora Mills:

Son fotosensibles y jamás deben ser expuestos a una claridad superior a esta. Les produciría erupciones, llagas y falta de aire en cuestión de minutos. A largo plazo podría ser fatal (Amenábar 26)

Hasta la conclusión, momento en el que los niños palpan la luz, una vez se revela toda la verdad, la única claridad que los ilumina es la del credo opresor que lleva al silencio, a la repetición mecánica de las oraciones y al confinamiento en la oscuridad que no les permite recordar ni crecer y, en consecuencia, tampoco liberarse. De hecho, la primera aparición de Anne y Nicholas —encerrados en su habitación celda-, los muestra pálidos y enunciando automatismos, ensalzando

$19 \mathrm{La}$ luz es un elemental tematizado en el film, un personaje más. También el quinqué preside la mesa de la sala de estudio en torno a la cual Grace y los niños leen pasajes de la Biblia. La madre imparte catequesis, habilitándolos en el camino de la purificación, aunque, en esencia, los esclaviza al credo del sometimiento. No es casualidad que la casa permanezca sin luz eléctrica desde el asedio de los nazis, lo cual permite a Grace recrear un escenario de claroscuros - zonas iluminadas y reprimidas - a su antojo. Es loable en este sentido, el trabajo del director de fotografía Javier Aguirresarobe, quien logra una pátina de tenebrismo fundamentado, con contrastes de dramatismo límite, además de la fusión sutil entre la luz y las sombras en los espacios de incertidumbre (aura liminal en la que se difuminan los límites).

Erigiéndose en referente de luz, Grace magnetiza a los niños, los liga a su seno, como faro guía, haciéndoles creer que, lejos de ella y su tutela, se perderán en la oscuridad circundante, sufrirán esa desorientación que ella subraya:

Aquí, la mayor parte del tiempo uno no sabe dónde está. No se puede apreciar si ahí hay una mesa, una silla, una puerta, un aparador... o uno de mis hijos jugando al escondite. (Amenábar 22).

${ }_{20}$ Considérese la siguiente conversación entre Grace y la señora Mills:

SEÑORA MILLS: ¿Nunca salen fuera a jugar?

GRACE: No durante el día. Por eso compramos este caserón y lo vaciamos de muebles. Para que jueguen y corran en las habitaciones sin tropiezos, para que no sientan que viven encerrados en una especie de cárcel.... aunque es inevitable; pobrecitos míos. (Amenábar 48) 
la única luminosidad - metafórica - a la que aspiran — "Bendigo, en la luz del día,/a Jesús que me la envía” (Amenábar 24) - junto con el haz de luna que baña su dormitorio cuando el supuesto fantasma del niño - trasunto de ambos en la realidad del quiasmo - descorre las cortinas para liberar el inmenso ventanal, reclamando también el lecho y demostrando, así, la incompatibilidad en un mismo espacio entre las presencias del pasado y el presente, actantes ya finados y nuevos propietarios de la mansión (dialéctica de desterritorialización y apropiación).

Otro de los elementales figurativos asociados a la antagonista son las llaves (quince, en concreto), que ella porta y de las que entrega copia a la señora Mills con claras indicaciones y restricciones sobre cómo proceder. Grace coarta, de este modo, el libre movimiento dentro de la casa, condicionando qué puertas de entre un total de cincuenta - pueden abrirse, cuáles han de cerrarse y, en puridad, a qué estancias se puede acceder, dependiendo, nuevamente, de la incidencia de la luz, que condiciona el comportamiento y el movimiento en el interior de la mansión. Como podrá inferirse, las puertas y los cortinajes que cubren las ventanas operan como armas de opacitación y enclaustramiento que mantienen a los inquilinos fuera del alcance de toda claridad o entendimiento más allá del que la máxima autoridad en la casa exige.21 De hecho, es norma inquebrantable que una puerta se abra sólo cuando la inmediatamente anterior se ha cerrado, logrando, de este modo, aislar la luz y evitar su propagación, como si de un elemental infecto o contagioso se tratase. Grace afirma:

Aquí lo único que se mueve es la luz. De un lado a otro... todo cambia ... [E]s bastante incómodo, por no decir insoportable. Y la única manera de sobrellevarlo es manteniendo la cabeza fría (Amenábar 32).

Así, la feminidad "empoderada" huye de la luz, del ayer, del horrible suceso que trata de reprimir y negar en todo momento - la niebla que se cierne sobre la casa representa lo ominoso que sólo se disipará cuando la progenitora y sus vástagos asuman la verdad - para seguir abriendo puertas, guiándose por una claridad falaz. Su premisa es no hundirse en ese abismo que permanece latente y se revela en sueños - la sublimación del trauma que la lleva al grito-, hacer que su

\footnotetext{
21 Las transiciones entre planos funcionan también como puertas metafóricas en el discurso. Es habitual el fundido encadenado junto con un "tempo" pausado, lo cual traslada una sensación de fluidez dentro de la normalidad, linealidad armónica en consonancia con la asertividad y seguridad que pretende transmitir la madre. Con todo, significativos son, de igual modo, los fundidos en negro, puntuales y reveladores, que impactan al espectador tras el eco de alguna sugerencia o anunciación velada, puntos de incertidumbre y anticipo del quiasmo. Esta interrupción drástica de la secuencia se da, por ejemplo, cuando la señora Mills regresa a la cocina y Anne repite: "Sí pasó" (Amenábar 29), en alusión a sus sospechas en torno al infanticidio.
} 
realidad y supuesta autosuficiencia, su embarcación y su tripulación, se mantengan a flote adoptando sus normas de contención. Es la propia Grace la que parece sugerir esta asociación alegórica al referirse a su entrega y sacrificio:

La casa es igual que un barco. Se debe contener la luz como si fuera el agua, abriendo y cerrando las puertas. ¡Está en juego la vida de mis hijos! (Amenábar 54).

Al timón de dicha realidad creada en el apartamiento, a partir de su prisma coaccionador -insistimos que, en un principio, alineado e identificado empáticamente con la progenitora, el espectador no llega a recelar de sus consignas - Grace cree estar formando a sus hijos en un camino de perfección, cuando, en realidad, el único movimiento posible para ellos es el tránsito en bucle y el retraimiento, toda vez se encuentran atrapados en la dimensión de la mentira y en el más allá, en la invisibilidad desde el prisma objetivo, por más que tangible y real parezca el microuniverso que habitan. No en vano, cuando Anne planeta sus dudas - indaga y trata de interpretar sin mediatización - acerca de lo que espera tras la muerte, con lucidez sorprendente, a pesar de la subyugación de sus pensamientos y la minimización de su capacidad de enjuiciamiento, Nicholas afirma: "Nunca iremos a ningún sitio" (Amenábar 110).

Ante esta situación de asfixia y parálisis, la proyección del quiasmo, la posibilidad de otras realidades alternativas y simétricamente invertidas, va cobrando peso gradualmente en pantalla, como si su luz disidente se fuese filtrando sin remedio en la dimensión unívoca y quebradiza de Grace.

\section{Interpelando al fantasma: la disidencia textual como deconstrucción}

Al hilo de lo apuntado, resulta imperativo delimitar las tres dimensiones que conviven en el film para entender como lógica la paulatina adscripción de nuestra lectura a las interpretaciones emergentes y, con ello, valorar en su medida el juego de equívocos que plantea Amenábar a la hora de definir la otredad. Aclaremos, como idea fundamental, que la película hace uso del "mise en abyme" como estructura de jerarquía narrativa asumida ya desde los créditos del film22, con la voz de Grace abocada a referir una historia sobre la creación 
del mundo a partir de la nada $\mathrm{y}$, análogamente, impeliéndonos a considerarla entidad motriz enunciadora a partir de la cual se genera el resto de textos, reduplicaciones ilustrativas y refrendadoras de esa realidad que ella concibe e impone a los demás.

Como ya se ha apuntado, durante gran parte del metraje, interpretamos los acontecimientos a través del punto de vista de la madre y, en dicho nivel de percepción sesgado — primario y de textualidad más cuantitativa_-, los otros, el antagonismo invasivo, está representado por presencias invisibles, manifestaciones incorpóreas, acusmáticas, a partir de ruidos y voces que ocupan la segunda dimensión (imagen 6) 23 y cuya plasmación más tangible es los dibujos de Anne, en los que identificamos a un niño - Víctor-, a sus progenitores y a la que se supone entidad maléfica epicéntrica, una anciana de aspecto siniestro y amenazador.24 La sorpresa del film se produce, precisamente, cuando Grace y sus dos hijos se volatilizan en escena y cobran fisicidad las presencias previamente invisibles, los participantes en la sesión de ouija (imagen 7), urgiéndonos a la perplejidad ante la confirmación del quiasmo más crucial dentro del film. Así, en la conclusión de la historia, la realidad de los personajes con los que nos hemos identificado pasa a un segundo plano, suplantada por la, hasta ese momento, dimensión latente. Se revela, de este modo, la terrible verdad, haciéndose manifiesto que Grace, sus hijos y los sirvientes están muertos, 25 son los espectros en la morada, los verdaderos otros, entidades residuales que pertenecen al pasado - los sirvientes murieron de tuberculosis en

narrador y poseedor de la palabra; por otra, se habla de la creación — fundamental en un discurso en el que la progenitora pretenderá preservar y proteger los límites de su propia creación-, con la consagración, empero, de su contrario - la destrucción a la que se aboca debido al abuso de poder; finalmente, ni la narradora ni los narratarios — niños, según revela la propia voz - aparecen en escena, por lo que este podría ser un guiño prospectivo a la esencia incorpórea de los protagonistas del film.

23 No en vano, el film presenta la lucha y reivindicación de Grace por conservar su papel de madre y máxima autoridad en la casa frente a aquellos que, supuestamente, la han invadido. No en vano, como afirma Huggan: "Ghost stories are to do with the insurrection, not the resurrection of the dead" (353-54).

${ }_{24}$ En las constantes reduplicaciones y reflejos entre dimensiones, resulta recurrente el número tres, posible trasunto de la Santísima Trinidad, no accidental en un film impregnado de referencias bíblicas. En la supuesta dimensión real, contamos con dos unidades de tres actantes, por una parte, Grace y sus dos hijos, además de la señora Mills, Edmund Tuttle y Lydia, quedando Charles perdido en la zona intersticial, como ratificación de la ausencia. En la dimensión de "los otros", tenemos a Víctor, además de sus padres (el señor y la señora Marlish), siendo la médium otro personaje a medio camino entre la realidad y su simulacro.

${ }_{25}$ La espectralidad de los sirvientes se manifiesta en un momento especialmente dramático del film, sirviéndose Amenábar del montaje alternado: por una parte, el descubrimiento de las tres tumbas en el jardín, junto al árbol disecado, una vez el señor Tuttle ha retirado la hojarasca para iniciar el proceso de desvelo, y, por otra, la imagen "post-mortem” de los sirvientes que Grace halla en su particular despertar progresivo a la realidad. 
el siglo XIX; Grace y sus hijos, tras la Segunda Guerra Mundial.26 Así, el espacio de lo doméstico y la máxima autoridad legitimada en él se manifiestan como proyección de la monstruosidad.

La tercera dimensión es la intersticial o liminal, aquella en la que las dos anteriores confluyen, la que evidencia la coexistencia entre vivos y muertos, anunciando el sorprendente giro de los acontecimientos a la postre. En este sentido, la mansión es, lógicamente, el ámbito fundamental dentro del discurso y existe como realidad tangible, objetiva e inalterable,27 siendo, al mismo tiempo, vórtice de confluencia entre el ayer y el presente, perímetro de interacción, pues, entre las tres dimensiones. Se trata de un espacio escénico, una interioridad sobre la que se proyecta la visibilidad o invisibilidad de unos y los otros, dependiendo del momento de la narración.28 Más específicamente, esta tercera dimensión liminal se explicita a través de revelaciones fundamentales en la historia,

26 La premisa argumental que articula el punto de vista eje de la historia a través de la lente de un personaje que no es consciente de estar muerto es deudora del film de M. Night Shyamalan El sexto sentido (The Sixth Sense, 1999). De hecho, son varias las películas que, de un tiempo a esta parte, han optado por una visión más inclusiva y normalizada del espectro, no como el referente antagonista de otredad sino como el yo confesional que nos refiere sus cuitas. Tómense en consideración, en este sentido, dos películas fundacionales y de corte independiente que subvierten y actualizan innovadoramente el concepto de fantasma: I am a Ghost (H.P. Mendoza, 2012) y A Ghost Story (David Lowery, 2017).

Aviva Briefel se refiere a esta tipología de films como narraciones de "spectral incognizance", ritos de iniciación que sirven a los espectros protagonistas para tomar conciencia de su estado y aceptar su muerte física — proceso de adaptación empírica (Juan-Navarro 24) - también a partir de la asunción psicológica:

Narratives of spectral incognizance are predicated on the idea that dying is not only a corporeal failure, but also a cognitive act: those who overlook their deaths are not really dead. Instead, they lead a liminal existence scattered with clues signaling their passing; they can only transition into real death once they have interpreted these clues properly. (97)

27 En su discurso de visibilidad cuestionada y a pesar de la recurrente sensación de desorientación, Amenábar optó por una representación detallada de la casa - fundamentada en una impoluta puesta en escena, una planificación detallada de la composición y la alternancia de encuadres generales o "establishing shots" con planos profundidad y detalle-, lejos de una visión impresionista o evanescente del espacio. El director hace de la mansión un perímetro necesariamente habitable, valiéndose especialmente de la perspectivación con puntos de fuga y los "travellings" que impelen a la inmersión espectatorial en el escenario. De hecho, en la génesis del film, acompañamos a Grace y a los singulares sirvientes en una ronda de reconocimiento por la casa. A lo largo de la película, se visibilizarán manifiestamente el vestíbulo, la sala de música, la sala de juegos, la cocina, la sala de estar, las escaleras, los descansillos de estas, el dormitorio de los niños, el dormitorio de Grace o la sala de estudio.

Otra cuestión es el exterior, de delimitación menos precisa, en un ambiente más lúgubre y amenazador, espacio alegórico de la muerte — hojarasca y tumbas—, la tragedia —el árbol de ramas retorcidas - y la vida en suspensión — niebla. De hecho, la Isla de Jersey se erige en espacio suspendido en la nada, entre Inglaterra y Francia (Bruce 34 y Juan-Navarro 16).

28 Apoyándose en los fundamentos teóricos de Julia Kristeva, David Sibley sostiene que esta anulación de las fronteras, confusión entre estados y categorías dentro de la casa, incertidumbre esencial, la definen como un espacio de incertidumbre esencial y abyección. 
momentos casi epifánicos. Consideremos, por ejemplo, la escena en la que el espectador acompaña a Grace — de riguroso luto, dejando a entrever la pérdida que, por equívoco, podría remitir a la ausencia del esposo, pero la desemantiza, más bien, como madre, por el infanticidio - en su búsqueda de los otros en el piso superior de la mansión, llave en mano y ejerciendo su autoridad al moverse libremente y abrir puertas a su antojo, tratando de confinar y combatir a los extraños para expulsarlos de los límites del ámbito doméstico y proteger, así, a los suyos. Una vez accede a la estancia del piso superior — bañándose su faz de luz, significativamente-, aparece en encuadre alegórico todo aquello que permanece reprimido en su memoria - formas indistintas cubiertas con guardapolvos - $29 \mathrm{y}$, entre susurros y sonidos que delatan la presencia de intrusos en la casa,30 Grace va destapando el mobiliario y las estatuas con la intención de identificar a los referentes de lo siniestro. La etapa de disociación con respecto a la otredad en el espejo - Lacan- tiene, sin embargo, consecuencias escalofriantes para la madre, pues lo único que halla en la habitación es el reflejo de sí misma (imagen 8), efecto premonitorio de lo que sobrevendrá en la conclusión del film. 31

También es liminal la dimensión evanescente y dominada por la niebla que rodea la casa, el allende, lo contextual, más allá del jardín y la verja exterior, la frontera que trasciende Grace al encuentro de respuestas y la ayuda del sacerdote, un espacio sin orientación posible tras el trazado de la senda entre árboles con punto de fuga "ad infinitum" en el que la viuda se topa con el espectro de su esposo Charles. Además, el descubrimiento del libro de fotografías "post-mortem" abre otra falla más en la realidad insostenible que

29 Se trata de una galería de iconos fantasmagóricos que adoptan la imagen tradicional del espectro cubierto con sábana.

30 Frases como "Ella está aquí, ella está aquî" (Amenábar 72) o “¡Nos está mirando!” (72) son claramente inteligibles, tanto para Grace como para el espectador — por ende, objetivables-, en planos con punto de vista omnisciente.

31 Afirman Altemir e Ibáñez:

Grace is caught between the desire to discover her new self and the fear of facing the monstrous other, which would mean death and consequently eternal damnation. (280)

La imagen compensatoria de la nueva realidad e identidad que Grace trata de fijar para disociarse de la otredad termina por liberar, precisamente, el monstruo interior, su propio reflejo. Reconocemos en esta deriva la articulación del segundo término del quiasmo a partir de una afirmación del primero. La enunciación de Grace es, como indicaría Rosalba Campra (2324) sustantiva, pues delimita el yo y sus circunstancias, pero, a la vez, define sus contrarios. Se trata de esa imposibilidad de erradicar y huir de nuestros miedos reprimidos a la que alude David B. Morris en su conocido ensayo "Gothic Sublimity":

The terror of the uncanny is released as we encounter the disguised and distorted but inalienable images of our repressed desire not from something external, alien or unknown but — on the contrary — from something strangely familiar which defeats our efforts to separate ourselves from it. (309) 
proclama Grace, desvelando prospectivamente a partir de esos enmarques de extrañamiento grotesco, la aparente vida en muerte - confusión de ambos estados - , justamente la que define a la madre, a sus hijos y a los sirvientes, la existencia en pena, la de los espectros encadenados al limbo de los otros. De hecho, ese libro de instantáneas siniestras presenta una laguna de incertidumbre - una fotografía ausente en sus páginas - que parece invitar al espectador a rellenarla con sus suposiciones, más allá de la asunción impuesta por Grace. No en vano, frente a los enmarques macabros, la señora Mills explica todo cuanto permanece reprimido en la mente de la madre:32

GRACE: ¿Sabe usted qué puede ser esto?

SEÑORA MILLS: Es un libro de fotografías, señora.

GRACE: Sí, pero todos están como dormidos. Mire.

SEÑORA MILLS: No están dormidos, señora... Están muertos. Es un libro de difuntos.

GRACE: Jamás vi algo parecido.

SEÑORA MILLS: En el siglo pasado era algo muy común. Se retrataba a los muertos con la esperanza de que su alma perviviera en la fotografía.

GRACE: Hay incluso retratos de grupo. ¡Y niños! Es macabro. ¿Cómo podía aquella gente ser tan supersticiosa? Yo lo habría prohibido.

SEÑORA MILLS: El dolor por la pérdida de un ser querido puede empujar a hacer cualquier cosa.

GRACE: Aquí falta una foto... en la última página.

SEÑORA MILLS: Quizá el álbum nunca fuera acabado, señora. (Amenábar 83-84)

\footnotetext{
32 En la onda de Barthes, quien considera que la instantánea es una suerte de emanación actualizada del referente (80), y Sontag, para quien toda instantánea es un acto de "memento mori” (15), Susan Bruce sostiene:

Photographs, like ghosts, possess the qualities of a revenant: they return from the past, ushering their content into our presence with an imperious insistence that we recognize and acknowledge them. (26)

En el caso de la fotografía "postmortem", la reviniencia se produce ya dentro del marco, antes de la recepción de la instantánea, con el simulacro que nos presenta al referente muerto deceso, por ende, ya consumado - como vivo. La fotografía inmortaliza esta falacia de modo que el visionado de la misma apenas permite una actualización vitalista del referente, por cuanto es la imagen de un muerto. Para la evocación revitalizadora tendríamos que tener esa imagen constatada del vivo — ausente en la instantánea—, si bien intuida a partir de la pretendida "domesticación" del deceso.
} 
Es evidente, asimismo, que la médium se desmarca como otro referente liminal en la historia pues representa — a través de su interpelación al más allá como aquella que, a pesar de su ceguera, ve lo que remanece oculto- el diálogo e interacción, la convergencia entre vivos y muertos, el ayer y el hoy, en la estancia en la que se desarrolla la sesión de ouija y desvela el quiasmo o inversión angular de la lógica asumida durante el desarrollo del film.33 De hecho, la sucesión de acontecimientos en el metraje representa el despertar paulatino inercia no reversible - de Grace y sus hijos a la espantosa realidad, llevándoles a la anagnórisis última.34 El discurso y los parámetros acomodaticios de aquella, sus reglas, sus prejuicios, la coacción de pensamiento o movimiento $\mathrm{y}$, en definitiva, el enclaustramiento e ideación ejercidos a través del uso de las llaves y la luz del quinqué se ven minados por las voces resistentes de aquellos que, conviviendo en su misma dimensión, conocen o intuyen el terrible suceso del ayer $\mathrm{y}$, por ende, interpelan acusadoramente a la progenitora como personaje enajenado. A diferencia del pequeño Nicholas, amedrentado y dependiente, Anne - quien también sufre cierta amnesia o trance post-traumático-35 establece distancia con su madre, recela de ella, subraya la mutabilidad de su carácter y el nerviosismo extremo que en ocasiones la ciega, lo cual le hacer intuir - casi recordar- ese momento oscuro de sus vidas que no consigue precisar. Es Anne también la que, ejerciendo de narradora hipodiegética, alarma acerca de la existencia de los otros en la casa, nominando referentes de poder alternativo:

GRACE: ¿Por dónde han ido?

ANNE: Por ahí, y por aquí... y también por allí ... Están en todas partes. Dicen que la casa es suya. (Amenábar 73)

Enfrentándose a las consecuencias — encierro y castigo — la pequeña se muestra más pragmática, cuestiona visceralmente los planteamientos de su madre y la imposición de todo credo heredado. Así, entre otros síntomas de disensión, Anne muestra sus reservas con respecto a dogmas bíblicos tales como que Dios crease el mundo en siete días o que en el Arca de Noé se pudiese cobijar a esa inmensa

\footnotetext{
33 Es en esa disfunción súbita donde radica el potencial del género. Afirma Marcia England: "horror occurs when boundaries are transgressed, when what is seen as normal suddenly becomes inverted" (354).

34 Recurso narrativo que consiste en la reformulación o replanteamiento - por parte de un personaje - de las bases de identidad y relaciones con el entorno. Por circunstancias, tal actante descubre una serie de datos que, hasta ese momento, le eran desconocidos y le permiten construir una imagen más depurada, razonada y sólida de sí mismo.

35 Lydia, la sirvienta muda, es epítome metafórico de las consecuencias de su tragedia particular. Incapaz de expresarse e interactuar, representa la imposibilidad de adaptarse a las nuevas circunstancias, justamente aquello por lo que lucha Grace, sin lograrlo a la postre.
} 
cantidad de animales.36 Dos escenas resultan harto ilustrativas al respecto; en una de ellas, Anne se queja a su madre, afirmando: "No puedes obligarme a pedirle perdón a la Virgen ... El otro día leí que el limbo es sólo para los niños que no han sido bautizados. Yo sî́" (Amenábar 61-62). Como respuesta, Grace reprime, de inmediato, el brote subversivo para fortalecer el statu quo que ella ha creado:

O sea que la chica lista ha aprendido a leer por su cuenta, ¿no es así? Muy bien. Puesto que lo encuentras interesante e instructivo, seguirás leyendo la Biblia, de pie, tres horas diarias hasta que le pidas perdón a la Virgen. (Amenábar 62)

Tras estas palabras, la madre abandona la sala, dando un portazo —el umbral impedido, nuevamente, como herramienta ejecutora del bloqueo-, jerarquizando y disponiendo autoritariamente para preservar el control. La otra escena se corresponde con la lectura de uno de los pasajes bíblicos en la sala de estudio. El texto vuelve a ejercer de reflejo del infierno que viven los niños en la mansión, así como de la necesidad de imponerse y destronar a la voz falaz. Reza la parábola:

En cierta ocasión, dos niños, llamados Justo y Pastor, se negaron a adorar a los dioses falsos de los romanos. Dijeron: somos cristianos y sólo adoraremos al Dios verdadero. El pretor romano trató de convencerles ... Después, mandó que los azotaran. Pero Justo y Pastor, en vez de tener miedo, estaban alegres y dispuestos a morir por Cristo. (Amenábar 36)

Otra voz resistente, ya se habrá inferido, es la que corresponde a la sirvienta Bertha Mills, cuya misión es hacer que Grace se reconcilie con su pasado y llegue a entender y asumir lo que sucedió. Su acción es tan sutil como gradual y constante; sometiéndose a los dictados de la déspota aunque, teniendo conocimiento pleno de lo acaecido, Mills deconstruye la visión distorsionada de Grace a partir de un lenguaje cargado de vagas referencias y ambigüedades que crean lagunas de incertidumbre en el discurso, activan la lectura activa por parte del espectador e ilustran cuán relativa y cuestionable es la realidad suspendida en

\footnotetext{
${ }_{36}$ En otro de los habituales juegos de espejos en el film, Anne, con velo de tul y vela, manipula una marioneta - cuyo mango tiene forma de cruz - ante el reflejo. Grace confunde a su hija con la imagen de la anciana siniestra y "ataca" violentamente a la pequeña. Tratando de combatir la otredad y en una nueva revelación sobre el espejo, Grace descubre su propia imagen, quedando retratada a los ojos de su hija y el espectador como referente antagonista, por su comportamiento desproporcionado y por las similitudes que guarda con la silueta del velo que manipula a su antojo a aquellos a quienes interpela, como si se tratase de marionetas en una casa de muñecas.
} 
la que habitan Grace y los suyos.37 Destaquemos la conversación que mantienen la señora Mills y Anne, actantes resistentes destacados hasta ahora, ejerciendo aquella de madre y hallando un punto en común con la pequeña. Ambas constatan la existencia de esa otra esfera de lo reprimido - podríamos hablar de una cuarta dimensión, pues- que representa el infanticidio y el suicidio, el recuerdo que Grace niega. Se trata también de una advertencia para el espectador, que, momentáneamente y ya como necesaria proclividad, se libera del punto de vista limitador de la madre, ausente durante la escena:

SEÑORA MILLS: Yo también los he visto.

ANNE: ¿Y por qué no se lo dice a mamá...? Así me tomará en serio.

SEÑORA MILLS: Hay cosas que tu madre prefiere no escuchar. Ella sólo cree en lo que le enseñaron. Pero no te preocupes. Antes o después, los verá. Y entonces, todo será distinto.

ANNE: ¿Por qué?

SEÑORA MILLS: Ya lo verás. Habrá grandes sorpresas. Habrá... cambios. (Amenábar 112) 38

Además de las voces contestatarias desde el seno de su ideación, también desde el exterior constatamos manifestaciones resistentes a la taxonomía de Grace, en un principio en forma de plasmación acusmática - ruidos que sobresaltan, llantos infantiles, sintomáticos de presencias espectrales en la casa-, al final, con la inversión de los planos, presencias tangibles que suplantan su autoridad a quienes tanto Anne como la señora Mills, no sometidas, no mediatizadas por

37 Según Altemir e Ibáñez (278), además de una evidente pugna por el cetro maternal, la fricción entre la señora Mills y Grace es un claro ejemplo de subversión y transgresión de clases.

38 Nótese, en el guión original en inglés, la recurrencia del verbo "see", incidiendo en el sentido de comprender e interpretar, llegar a entender el verdadero sentido de la situación, asignatura pendiente y urgente de Grace:

MRS. MILLS: Look, what an awful face you've got when you cry

ANNE: (crying) I don't care!

MRS. MILLS; There, there.

[Anne finally calms down]

MRS. MILLS: You listen to me. I've seen them too,

ANNE: You have?

[Mrs. Mills nods]

ANNE: Why don't you tell my mother? Then maybe she'll believe me.

MRS. MILLS: There are things your mother doesn't want to hear. She only believes in what she was taught. But don't worry. Sooner or later... she'll see them. And everything will be different.

ANNE: How?

MRS. MILLS: You'll see. There are going to be some big surprises. There are going to be... changes. 
aquella, han visto y ubicado en los espacios de la morada previamente - y completan el proceso de anulación y desterritorialización de sus presupuestos. Y entre los dos mundos, entre la dimensión de los vivos y los muertos, emergiendo de la niebla del ayer, la ya referida acción contestataria del esposo, quien también cuestiona la labor de Grace como madre y resitúa la alteridad, sugiriendo que ella es la contrafigura de la historia:39 "No hablo de fantasmas. Hablo de lo que ocurrió aquel día” (Amenábar 126), afirma Charles.

Será justamente a partir del desvelo de las presencias no tangibles en su relato, cuando Grace se aboque desesperadamente - coincide con una acentuación del tempo narrativo del film - a abrir todas las puertas y a descorrer todas las cortinas de la casona, ayudada por la libertad de movimientos que le permiten las llaves, el quinqué, la Biblia y la escopeta, arma que, en principio, parece representarla como icono arquetípico de la feminidad asertiva, pero que, en esencia, desvela su alienación y muestra la herramienta ejecutora del infanticidio velado (imagen 9). Al pretender exorcizar los demonios de su realidad mediante el periplo iniciático a través de los corredores y las estancias de la mansión - itinerario de descubrimiento que el espectador asume como propio a partir de la identificación con el punto de vista de la madre-, Grace mira al abismo, en busca de la monstruosidad, y — como en la habitación de los enseres cubiertos con sábanas - termina por descubrir un reflejo de sí misma, como monstruo, en el epicentro de la oscuridad.

En esa progresiva desemantización y desposesión de la autoridad y los atributos positivos del referente maternal, en la anulación de su interpretación impositiva de los hechos y lo circundante, resultan sumamente esenciales dos momentos clave de fragmentación de su macronarrativa pretendidamente omnisciente: primero - ya constatado_- cuando Grace desaparece de la escena y el punto de vista recae en aquellos que cuestionan su interpretación y dogmas; considérese, al hilo, el instante en el que la señora Mills, en conversación con Edmund Tuttle, anuncia que están a punto de acaecer cambios significativos, o aquel otro en el que Anne impele a Nicholas a escapar de la casa — "Ya estoy

\footnotetext{
39 Es otra de esas puertas que, contestatarias, no se abren a su voluntad. De hecho, durante el breve paréntesis con tintes oníricos — proyección de los deseos reprimidos de Grace-que supone el regreso del marido al hogar, asistimos a un momento más que ilustrativo. Grace llama a su esposo desde el piso de abajo y recibe un portazo — sonido acusmático y sombra de la puerta en movimiento- como respuesta. En la siguiente imagen, reforzando la esencia evanescente y caduca del pasado y la dimensión falaz de Grace, un plano cenital muestra al marido absorto, desorientado, perdido en el recuerdo. Previamente, durante la conversación en el dormitorio, la imagen de Charles no se refleja en el espejo del armario y deducimos que Grace habla consigo misma, proyectando su sentimiento de culpa. En este sentido, el postrero despertar de la esposa en un lecho a solas, sin la imagen de su marido, nos remite al inicio del film, los fantasmas de la soledad y el vaciado progresivo de dicha realidad.
} 
harta. Voy al bosque a buscar a papá” (Amenábar 139) — y ambos descubren la espantosa verdad en el jardín.40 Algo parecido ocurre cuando las puertas y los elementales dentro de la mansión comienzan a operar por sí solos, cuando no es Grace la que dicta los hechos, cuando no son sus llaves o su luz las que legitiman el siguiente paso y, consecuentemente, se multiplica la casuística - las puertas y la tapa del piano se abren solas, 41 las cortinas desaparecen-, quedando cuestionada la omnipotencia de la madre en el ámbito doméstico y constatándose la inseguridad del actante en sí misma a partir de los constantes soslayos, la multiplicación del acecho desde fuera de plano y el recurrente encuadre cenital o esa cámara que circunda la pose de Grace e ilustra su imagen monolítica acechada desde cualquier punto. La casa corporeiza lo reprimido, convirtiéndose en un lugar amenazador y hostil (Hock 147) que sume a Grace en recurrentes estados de pánico e histeria (Hock 153). Así se lamenta la figura autoritaria a medida que va sintiéndose gradualmente desposeída de autoridad:

¡Durante cinco años de ocupación, me las arreglé para que ni un solo nazi cruzara el umbral de esta casa! ¡Y ahora hay alguien aquí mismo, delante de mis narices, abriendo y cerrando puertas! (Amenábar 73)

Previo al desvelo de la incómoda verdad, cuando se descubren las tres tumbas de los sirvientes en el jardín — parodia del Jardín del Edén, con la fantasmática silueta de un árbol de la vida que, irónicamente, representa la muerte-, se

40 Perdidos en el bosque, en el espacio de lo insólito y lo ignoto, pretendiendo alejarse de esa madre que, también a ojos de sus hijos, parece haber perdido el juicio, Anne trata de consolar a su hermano:

NICHOLAS: Anne, creo que nos hemos perdido.

ANNE: Todavía no hemos salido del jardín, tonto.

NICHOLAS: Tengo miedo.

ANNE: Pues no haber venido.

NICHOLAS: Di algo.

ANNE: ¿Qué quieres que diga?

NICHOLAS: No sé, cualquier cosa.

ANNE: A ver... me llamo Anne y estoy andando. Estoy andando y me llamo Anne... (Amenábar 144)

Por más que la última afirmación de Anne parezca mera y absurda enunciación espontánea que evita el silencio y mantiene la mente entretenida, no dejando que el miedo la domine, estas dos frases se articulan en inversión, precisamente, a partir del principio del quiasmo y, a la vez, constatan la capacidad de la niña a la hora de interpretar y describir al detalle y literalmente, sin manipulación matriarcal, la realidad.

${ }_{41}$ En la gradual disociación entre Grace y la verdad o fiabilidad, el punto de vista juega un papel fundamental. Así, a pesar de que, antes de acceder a la sala del piano, el espectador se sitúa con ella ante el umbral, acompañándola como testigo empático en su trayecto de apertura legítima de puertas y abocándose a la interpelación de la otredad, una vez Grace entra en la sala, el contraplano desliga al espectador de su visión y lo sitúa en el seno de la estancia, a la espera de su irrupción, focalizando a la madre en el punto de fuga, resituándola como ajena a nosotros, como esa otra que accede al interior. 
produce otra proyección especular más que significativa: Grace y los niños permanecen en el interior de la casa mientras la señora Mills y sus dos acompañantes acechan desde más allá del umbral. Nuevamente la puerta - la de acceso principal a la mansión - guarda un simbolismo connotado por cuanto no es, en esta ocasión, una superficie de madera que opaca lo que hay a un lado y a otro sino que se trata de una cristalera a través de la cual son claramente visibles las siluetas a contraluz y sumidas en la niebla de esos a los que vemos como entes invasores del ámbito doméstico (imagen 10). De hecho, interior y exterior, supuestos vivos y supuestos muertos, interactúan estableciendo un diálogo de simbiosis. Grace abraza protectoramente a sus hijos y, una vez más, trata de situar la otredad fuera de sí misma:

SEÑORA MILLS: íbamos a decírselo tarde o temprano. Sólo queríamos encontrar el momento oportuno para hablar con usted.

GRACE: ¿Sobre qué?

SEÑORA MILLS: Sobre la casa... sobre... la nueva situación.

GRACE: ¿Qué situación?

SEÑORA MILLS: Debemos aprender a convivir... los vivos con los muertos. (Amenábar 153)

En esencia, la puerta sirve como espejo y delineación simétrica entre los tres actantes que permanecen fuera y esa triada que recela en el interior, ocupando todos la misma dimensión y compartiendo estado redivivo. Es justamente en este momento de desorientación para el espectador, abocados a la conclusión, cuando se da otra escena fundacional que ejemplifica la lectura activa y alerta de los acontecimientos por parte del espectador. La filmación sigue a Anne y Nicholas, que huyen a su dormitorio y cierran la puerta a la cámara testigo, con la que nos identificamos. Después, los niños abren otra puerta — la del armario- y la vuelven a cerrar ante nuestros ojos, quedando el espectador, en este caso, ante un espejo, ante un reflejo, uno de tantos en el laberinto de proyecciones de desidentidad en el que quedamos atrapados durante el visionado del film.42 Es manifiesta la intención del realizador con este discurso necesariamente limítrofe - se aboca al fuera de plano, a la deconstrucción de la certidumbre, al cuestionamiento de la realidad, al solapamiento entre dimensiones- de plantearnos el reto constante de la reescritura y redefinición de nuestra identidad, la necesidad de mirarnos a nosotros mismos y repensarnos para tratar de fijar

\footnotetext{
42 Abundando en la importancia de las puertas, su apertura o cierre, esta que corresponde al escondite de los niños aterrados es abierta simbólicamente por la anciana, que ha iniciado la sesión de ouija y establece contacto definitivo con los fantasmas para precipitar el inesperado final de la historia.
} 
nuestra existencia en una realidad movediza en la que se borran los límites entre lo factible y lo irreal, donde se confunden y confluyen los vivos y los muertos, siendo estos de fisicidad tan tangible y veraz como aquellos.

\section{El quiasmo y la relectura inversa: conclusión}

Cuando Grace cambia la escopeta por un rosario y sube al piso superior, abre la última puerta a la verdad, la "espectralización" de los supuestamente vivos y la humanización de los que han permanecido excluidos en el espacio de lo siniestro.43 La médium desvela y fija el quiasmo e inversión fundacional del film, a pesar de la lectura resistente y desesperada de Grace y sus hijos — “ ¡No estamos muertos! ¡No estamos muertos! ¡No estamos muertos!” (Amenábar 158)_, como enunciación subyugada que necesita de la mediadora - la escritura automática - para manifestarse. Una vez los vivos abandonan la casa, el tempo del film decae notablemente en su anticlímax, sumiéndose en un trance confesional, estremecido, en el que la madre - en una imagen de "pietà" impactante, un enmarque hagiográfico casi (imagen 11) — asume su culpa:

Al principio no entendía qué hacía con la almohada en mis manos. Ni por qué no os movíais. Entonces lo supe. Había sucedido. Había matado a mis hijos. Cogí el rifle, me lo puse en la frente... y apreté el gatillo. (Amenábar 160)

Y al asumir que es consciente de la verdad epicéntrica del film, Grace deja de ser la progenitora empoderada que todo lo sabe para mostrar su incapacidad y limitaciones a la hora de dar respuesta a las dudas planteadas por los niños cuando estos preguntan si volverán a ver a su padre o dónde está el tan renombrado limbo:44

Ni siquiera sé si existe el Limbo. Sé lo mismo que vosotros. Pero sí sé que os quiero. Siempre os he querido. (Amenábar 164)

\footnotetext{
43 Susan Bruce se refiere a esta inversión concluyente como "misrecognition of the ghostly" (22). Grace y los niños son evidente manifestación del "grotesque body" sobre el que teorizan Mikhail Bakhtin (310) y Mary Russo (325): se trata de cuerpos sin identidad fijada, sometidos a un proceso y cambio en pos de la definición en el que, sin embargo, se descomponen, se corrompen y difuminan.

44 Además de las evidentes concomitancias que se pueden establecer entre los modos de filmación estilizada o la cuidada composición de planos por parte de Amenábar en este film y la caligrafía fílmica de Hitchcock, Los otros también es deudora de la maestría del director inglés en su gradual y sistemática construcción del suspense, sin obviar - estableciendo una comparación específica con Psycho (1960) — la sensación de orfandad que sufre el espectador una vez descubre que el personaje con el que se ha identificado a lo largo del metraje, ha trasladado, en realidad, una visión falaz, psicópata y manipuladora de la realidad.
} 
Desacreditada, su discurso ha dejado de ser convincente. El infanticidio y suicidio la presentan como ogresa y monstruo - "the monstrous feminine" -45 más que como madre, además de pecadora, contraria a los dogmas religiosos que profesa y en los que ha tratado de instruir a sus hijos. Con todo, ella persiste en su cegazón, se redime y se rearma de fe, asumiendo estar a la altura ante lo que considera una segunda oportunidad que Dios le concede.46 Por su parte, liberados ya simbólicamente del yugo de la oscuridad, Anne y Nicholas buscan la luz, la palpan y se muestran inermes a la fotofobia. La familia parece unida de nuevo, refrendándose a partir de una cantinela de asertividad y legitimidad pretendida que sugiere la madre: "Y esta casa es nuestra... Repetid conmigo, niños; la casa es nuestra, la casa es nuestra...". Esta duplicación de la frase tematizada no es sino fórmula de confirmación de una realidad para la que — de nuevo a través de la lente de Grace - no debe haber ya posible inversión de términos o quiasmo enajenador. En la medida en la que la enunciación se repita — con sinergia de voces, nuevamente homogeneizándolas y canalizándolas unívocamente-, no habrá lugar u opción para el eco invertido de un segundo término —el opuestoya que sólo persiste en secuencia, multiplicándose y reforzándose, el significado del primero.

Con todo, esta no es sino otra verdad relativa más que cuestionable, otro simulacro de autoconvencimiento por parte de Grace que, a estas alturas, el espectador sabe interpretar entre líneas. De hecho, los últimos fotogramas presentan el interior de la casa a través del encadenado de planos vacíos con la voz acusmática de Grace y sus hijos, lo cual ratifica la desterritorialización física del espacio doméstico y la presencia incorpórea de los espectros. Además, el plano en retroceso final se aleja de la fachada de la casona, distanciándose con él también el espectador, que permanece en la dimensión de los vivos mientras los fantasmas quedan desplazados al punto de fuga, en el encuadre del ventanal, como una fotografía "post-mortem", ligados a la mansión, al espacio de la

45 A partir del concepto de Creed (68), Altemir e Ibáñez especifican:

The mother-child relationship is central to the figure of the monstrous feminine, as the child at once seeks to separate from the mother and remain in the maternal relationship. The mother plays her role by preventing the child from extricating by refusing to abdicate control. (355)

${ }_{46}$ Como Lucifer, como Adán y Eva, Grace se ve privada de inocencia y gracia, de ahí que su nombre resulte un guiño irónico manifiesto. En puridad, el film representa la lucha del personaje principal por reconstruir su identidad a partir de los dogmas católicos (Altemir e Ibáñez 276), volver a una situación originaria en el Jardín del Edén, obviando que está muerta y compensando la tragedia a través de la redención o catarsis (Bruce 29):

El Señor en su infinita me estaba dando otra oportunidad. Diciéndome: "No te rindas, sé fuerte. Sé una buena madre. Por ellos. Pero ahora... ahora... ¿Qué significa todo esto? ¿Dónde estamos? (Amenábar 160) 
tragedia, condenados y atrapados en su limbo particular como entes residuales, desposeídos de todo (imagen 12).47

Más allá de las consideraciones de quienes habitan en el aislamiento, en el reducto cíclico del ayer, el plano general de la casa, la actualización del presente, muestra ahora que la propiedad no tiene dueño. De hecho, el cartel "En venta" impide la visibilidad de la fachada $\mathrm{y}$, por ende, la representa finalmente como otro significante evanescente, fantasmático, suspendido en la nada, a la espera de un nuevo inicio de ciclo, constatándose, de este modo, la circularidad del film.48 Es así como, a través del fundido en negro de la conclusión, Amenábar cierra la última puerta, aunque en nuestra imaginación, a través del mecanismo del quiasmo, todo regresa al principio, a la génesis del relato, a cada escena dentro de su desarrollo a fin de actualizarlas e interpretarlas desde las lecturas periféricas y a partir de su reflejo invertido.49

Los otros es una historia sobre la demolición de la unidad familiar como trasunto de toda realidad acomodaticia, sobre la necesaria problematización de las verdades absolutas y la taxonomía unívoca como simulacros, sobre nuestra realidad, identidad y existencia movedizas, planteando la forzosa definición de nuestra esencia a través de la alteridad. Amenábar multiplica el potencial de la ambigüedad, la dualidad y la incertidumbre del género gótico para, merced a una reescritura posmoderna, elevarlo a una dimensión metafísica (Juan-Navarro 28). El film se visiona como una parábola sobre la disolución de las lindes entre lo legitimado y la otredad, una advertencia sobre la imposibilidad de fijar y categorizar sin cuestionamiento lo que ha de estar en el centro y aquello que debería permanecer excluido; es una distopía que ilustra la inversión -e invasión - de lo doméstico, la cordura, lo familiar y la ambiguación de conceptos que gozan de predicamento positivo en nuestra taxonomía automatizada. Así, el amor se revela como auténtica arma letal de nocivas consecuencias cuando la enajenación lo torna en posesión, tal y como corporeiza el referente deconstruido de esa madre que, lejos de ser ejemplar, representa,

\footnotetext{
47 Hock (147) sostiene que Grace — como el resto de fantasmas en el film, añadimos nosotros - no pueden abandonar la casa pues son contingencia validada y posible sólo en el espacio específico vinculado a la tragedia.

48 Así lo refrenda también la señora Mills en la versión original a través de esa curiosa afirmación postrera "The intruders are leaving, but others will come". El espectador no puede evitar pensar en la posible ironía que, una vez clausurada la ambigüedad entre vivos y muertos, genera el par mínimo "leaving" vs. "living".

49 Redmon (256) se refiere al rédito y potencial significativo que garantiza un segundo visionado de películas en las que la sorpresa postergada hasta el final cambia por completo el sentido de los acontecimientos relatados: "one does not watch them the same way twice, but neither do these films become unwatchable after the reveal".
} 
justamente, el quiasmo oscuro de la virtud y la corporeización —aun inconsciente- de la maldad.

\section{OBRAS CITADAS}

Altemir Giral, Anabel, Ibáñez Rosales, Ismael. "Otherness in The Others. Haunting The Catholic Other, Humanizing The Self". Roman Catholicism in Fantastic Film: Essays on Belief, Spectacle, Ritual and Imagery. Ed. Regina Hansen. North Carolina and London: Mc Farland, 2011. 275-86.

Amenábar, Alejandro. Los otros. El libro. Madrid: Ocho y medio, 2001.

Arnold, Sarah. Maternal Horror Film: Melodrama and Motherhood. New York: Palgrave MacMillan, 2013. DOI: https://doi.org/10.1057/9781137014122

Bakhtin, Mikhail. Rabelais and his World. Bloomington: Indiana University Press, 1984.

Barthes, Roland. Camera Lucida. London: Vintage, 1993.

Becker, Susan. Gothic Forms of Feminine Fiction. Manchester: Manchester University Press, 2012.

Briefel, Aviva. "What Some Ghosts Don't Know: Spectral Incognizance and the Horror Film". Narrative Vol. 17, No. 1 (Jan., 2009): 95-110. DOI: https://doi.org/10.1353/nar.0.0011

Bruce, Susan. "Sympathy For the Dead: (G)hosts, Hostilities and Mediums in Alejandro Amenábar"s "The Others" and Postmortem Photography". Discourse, $\quad$ vol. $\quad 27.2 / 3 \quad$ (2005): 21-40. DOI: https://doi.org/10.1353/dis.2007.0001

Burkholder-Mosco, Nicole, Carse, Wendy. "Wondrous Material to Play On: Children as Sites of Gothic Liminality in The Turn of the Screw, The Innocents, and The Others". Studies in the Humanities. Vol. 32.2 (2005): 201-220.

Cambra, Rosalba. Territorios de la ficción. Salamanca: Renacimiento Iluminaciones, 2008.

Clover, Carol J. "Her Body, Himself: Gender in the Slasher Film". Representations 20 Misogyny, Misandry, and Misanthropy (Autumn, 1987): 187-228. DOI: https://doi.org/10.2307/2928507

Creed, Barbara "Horror and the Monstrous-Feminine: An Imaginary Abjection". Horror: the Film Reader. Ed. Mark Jankovich. London and New York: Routledge, 2002. 68-76. 
England, Marcia. "Breached Bodies and Home Invasions: Horrific Representations of the Feminized Body and Home". Gender, Place and $\begin{array}{lllll}\text { Culture, } & \text { vol. } & 13.4 & \text { (2006): } & \text { 353-63. }\end{array}$ https://doi.org/10.1080/09663690600808452

Friedman, Seth A. "Cloaked Classification: The Misdirection Film and Generic Duplicity”. Journal of Film and Video 58 (2006): 16-28.

Hock Soon NG, Andrew. Women and Domestic Space in Contemporary Gothic Narratives. The House as Subject. New York: Palgrave, 2015.

Huggan, Graham. "Ghost Stories, Bone Flutes, Cannibal Countermemory”. The Horror Reader. Ed. Ken Gelder. London \& New York: Routledge, 2000. 352-63. DOI: https://doi.org/10.4324/9780203138618-28

Juan-Navarro, Santiago. "Trapped In the House of Mirrors The Others as a Transnational Postmodern Gothic Thriller". Tracing the Borders of Spanish Horror: Essays on Contemporary Spanish Horror Cinema and Television. Ed. Jordi Marí. New York and London: Routledge, 2017. 15-33. DOI: https://doi.org/10.4324/9781315229249-2

Kristeva, Julia. The Powers of Horror: An Essay on Abjection. New York: Columbia University Press, 1982.

Lavik, Erlend, "Narrative Structure in The Sixth Sense: A New Twist in 'Twist Movies'?". Velvet Light Trap. 58 (2006): 55-64. DOI: https://doi.org/10.1353/vlt.2006.0031

Lewis, John. "Mother Oh God Mother...": Analysing the "Horror" of Single Mothers in Contemporary Hollywood Horror. Scope, 2 (2005). Web. 27 marzo 2019. <https://www.nottingham.ac.uk/scope/issues/2005/juneissue-02.aspx>

López, José L. De Almodóvar a Amenábar. El nuevo cine español. Madrid: Notorious Ediciones, 2005.

Moers, Ellen. Literary Women. Garden City, N.Y.: Doubleday, 1976.

Morris, Davis B. “Gothic Sublimity”. New Literary History 16.2 (1985): 299319. DOI: https://doi.org/10.2307/468749

Redmon, Allen H. “After Everything I've Seen": Rewatching Shutter Island as a Knowing Audience”. Adaptation 8.2 (2015): 254-67. DOI: https://doi.org/10.1093/adaptation/apv017

Russo, Mary. 2Female Grotesque: Carnival and Theory". Writing on the Body. Eds. Katie Conboy, Nadia Medina \& Sarah Stanbury. New York: Columbia University Press, 1997. 318-336.

Sibley, David. Outsiders in Urban Societies. New York: St. Martin Press, 1981.

Sontag, Susan. On Photography. Hardmonsworth: Penguin, 1979.

Torrance, Isabelle. "Retrospectively Medea: The Infanticidal Mother in Alejandro Amenábar's Film The Others". Unbinding Medea: Interdisciplinary Approaches to a Myth From Antiquity to the 21st Century. Eds. Heike Bartel, Anne Simon. New York: Legenda. Modern 
Humanities Research Association and Maney Publishing, 2010. 124-34. DOI: https://doi.org/10.4324/9781315084466-9

Whitesell, Lloyd. "Quieting the Ghosts in The Sixth Sense and The Others". Ed. Neil Lerner. Music in the Horror Film: Listening to Fear. New York: Routledge, 2010. 206-223.

Williams, Tony. Hearths of Darkness: The Family in the American Horror Film. Madison: Fairleigh Dickinson University Press, 1996.

Imagen 1: Simetrías y asimetrías del quiasmo visual. Tematización de lo latente y lo invertido

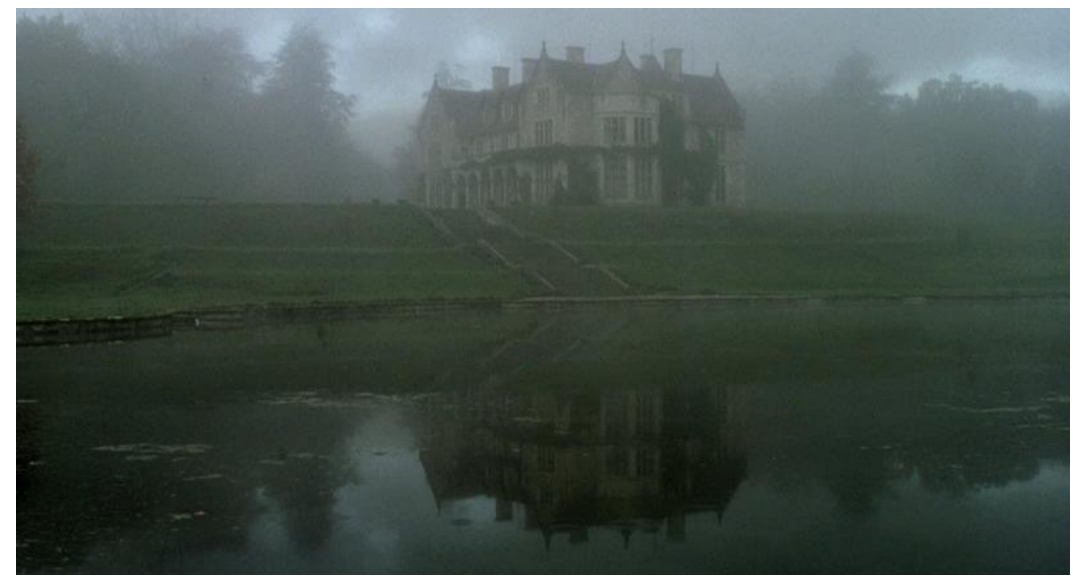

Imagen 2: Verticalidad por horizontalidad. Desautomatización de la mirada. Desequilibrio y psicopatía sugeridos

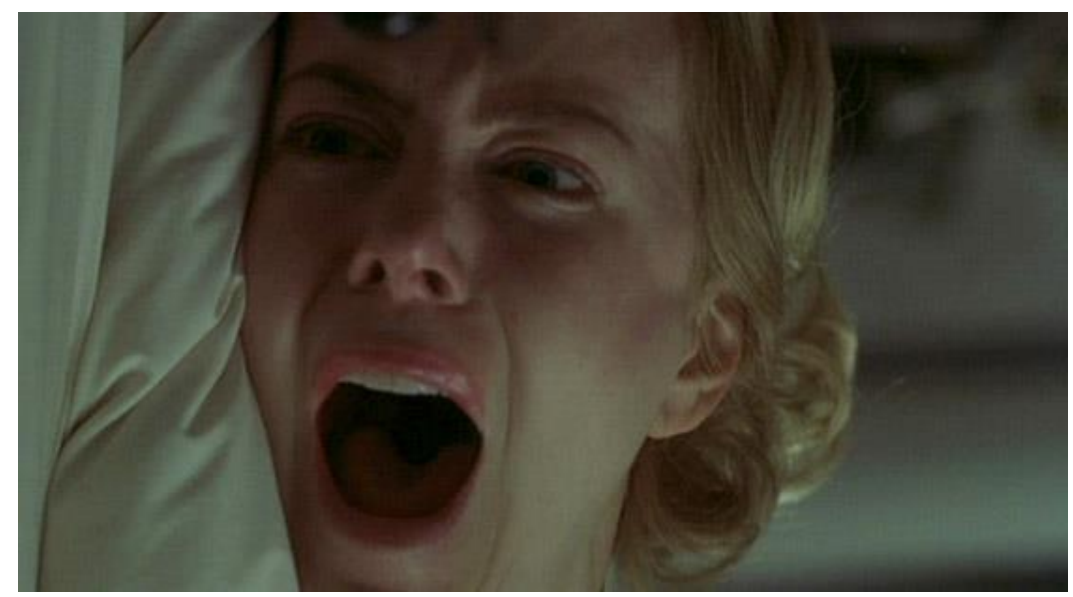


Imagen 3: Aleccionamiento en el credo unívoco

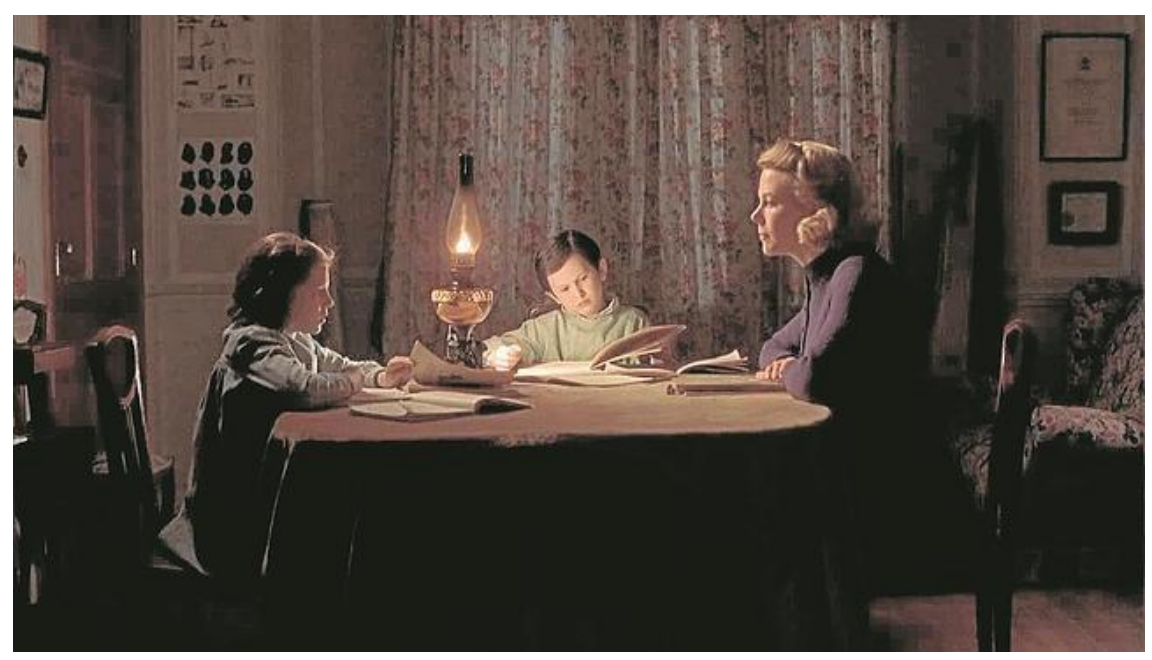

Imagen 4: Grace Stewart, guía y portadora de la luz legitimada

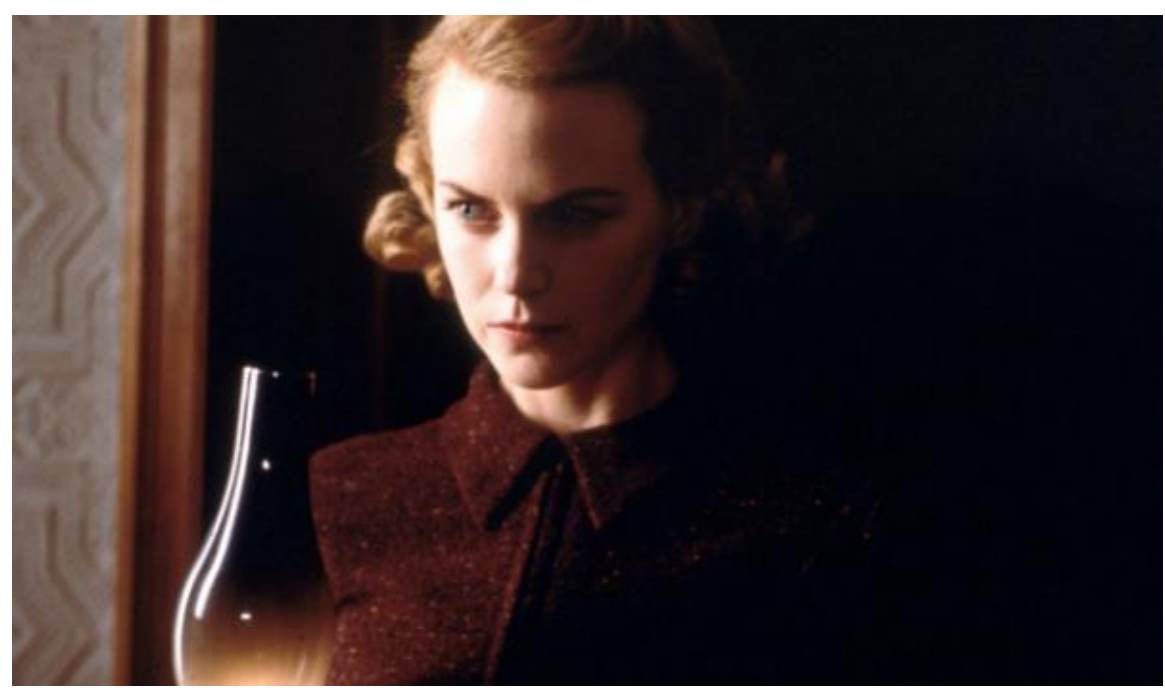


Imagen 5: La cárcel doméstica. Pavor y subyugación de Anne y Nicholas

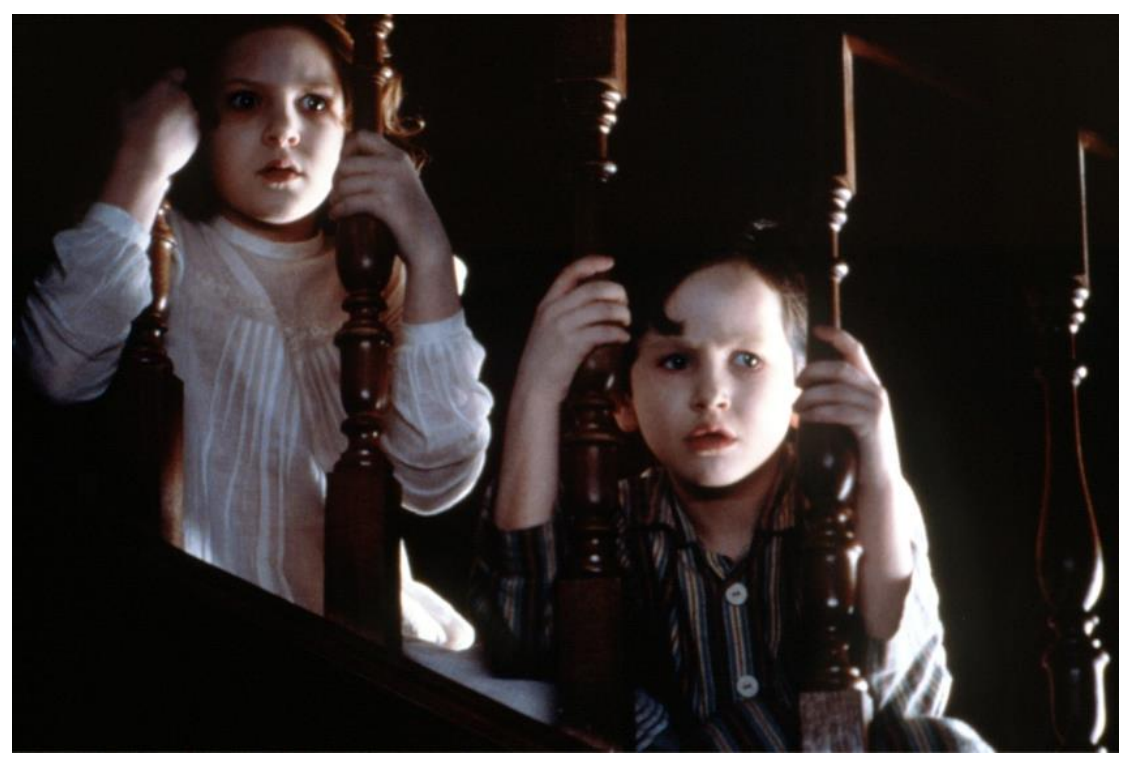

Imagen 6: Sonidos acusmáticos de la amenaza. Picado e interpelación fuera de plano — externalizada — de la otredad por parte de Grace

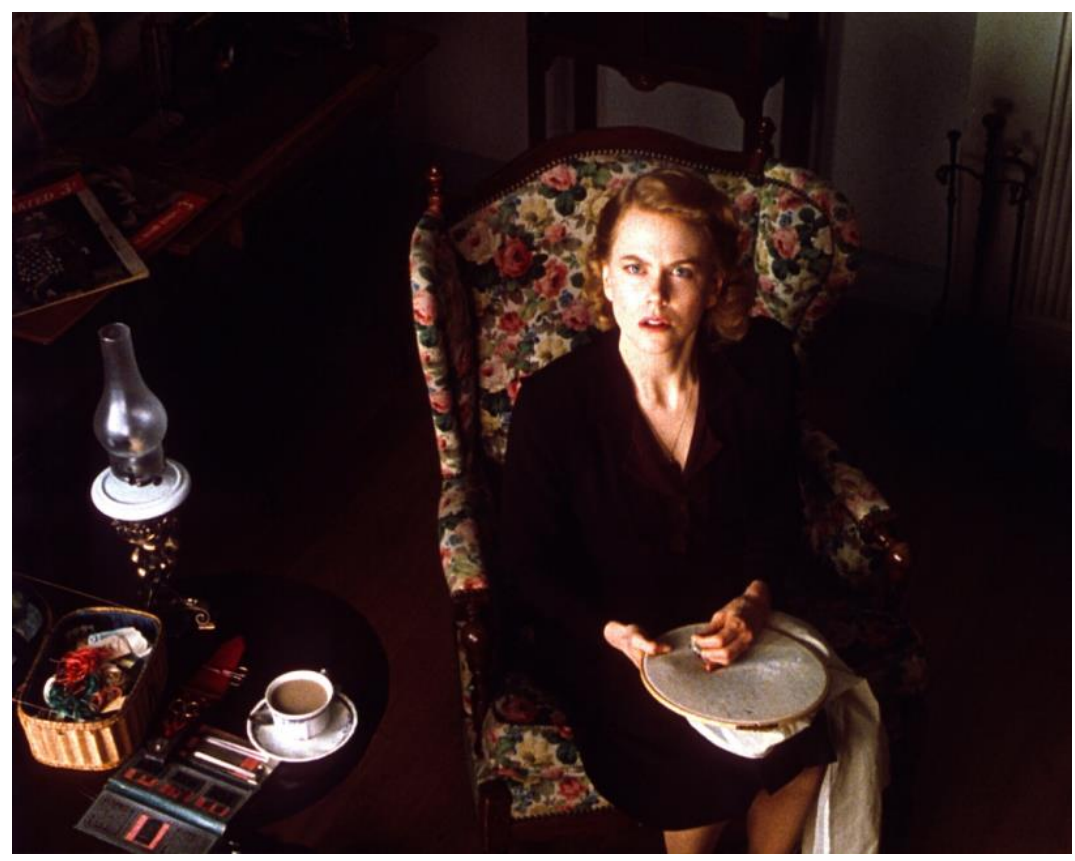


Imagen 7: Súbita invisibilidad y espectralización del referente de identificación y punto de vista en escena. La sesión de "ouija"

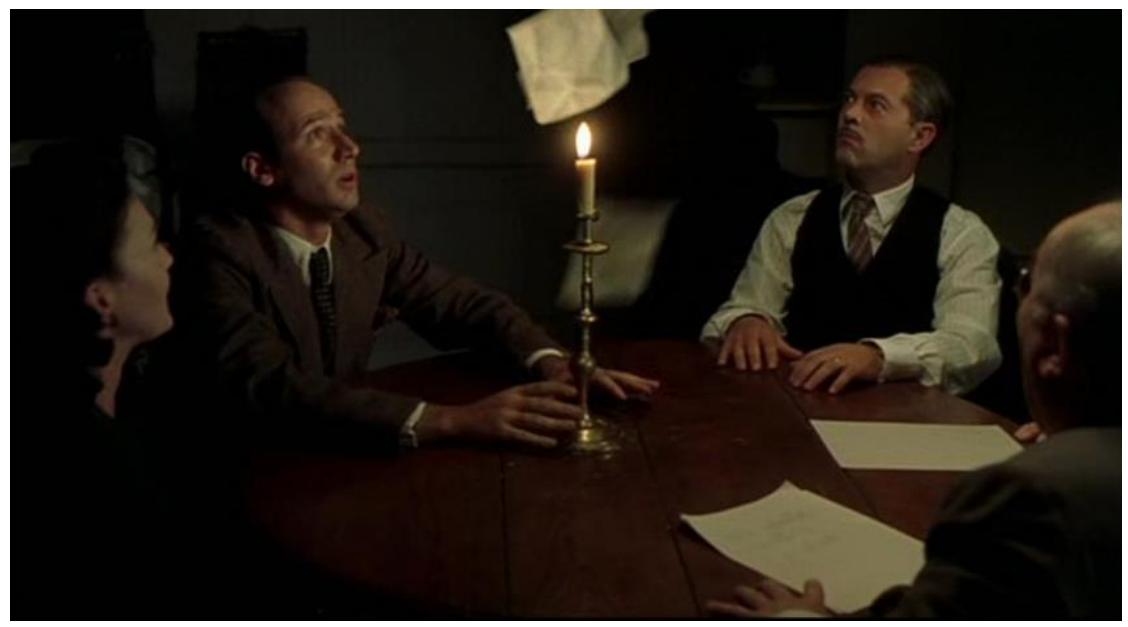

Imagen 8: Búsqueda, descubrimiento e interpelación de la antagonista

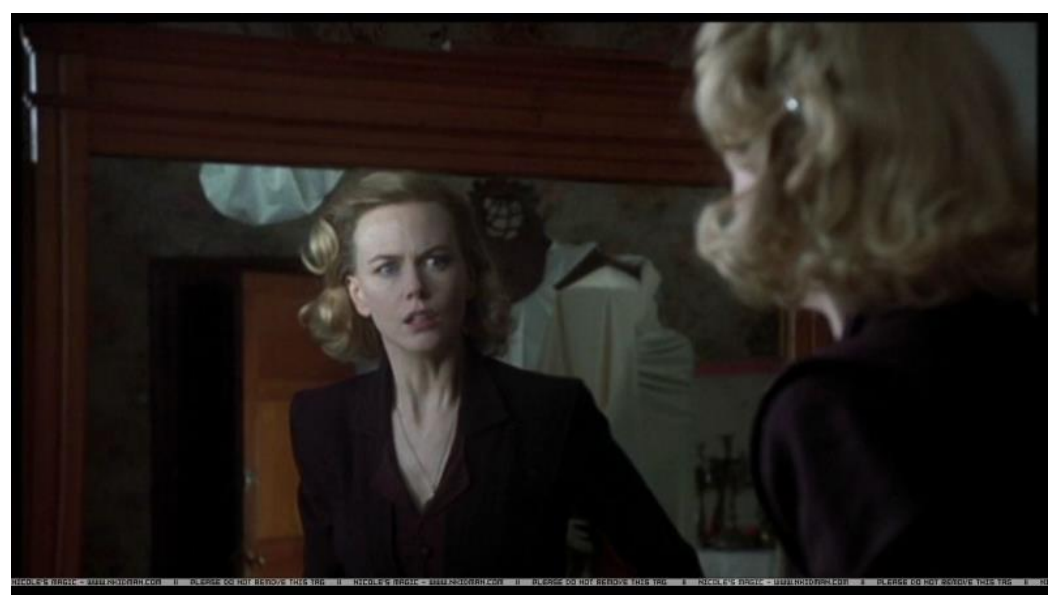


Imagen 9: Agresión frontal a la embocadura de plano. El espectador en el punto de mira

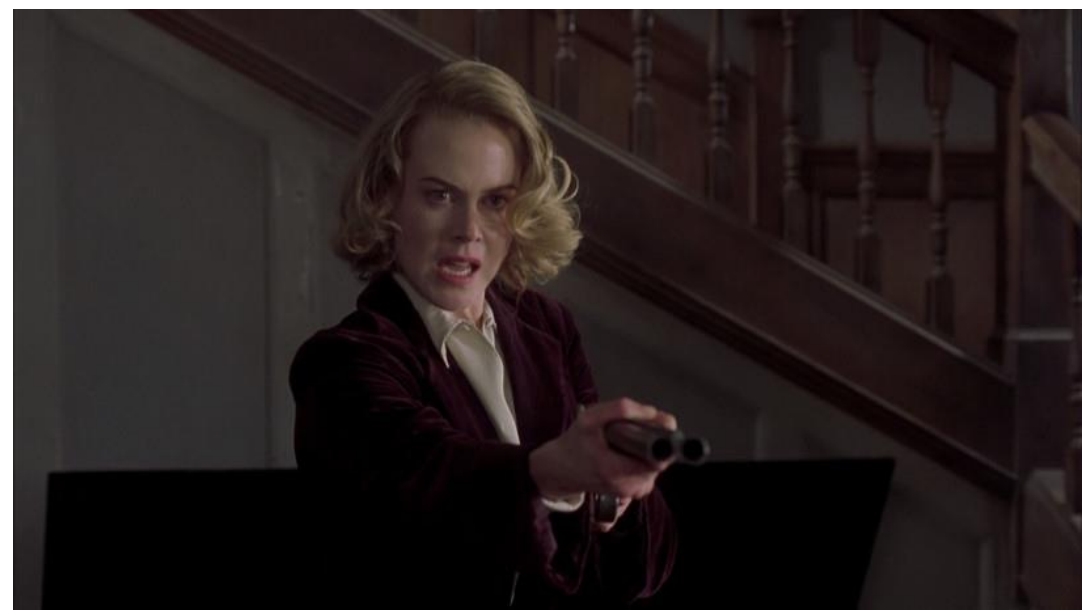

Imagen 10: Simetrías y quiasmo. Reflejos y revelación de muerte a uno y a otro lado del eje especular

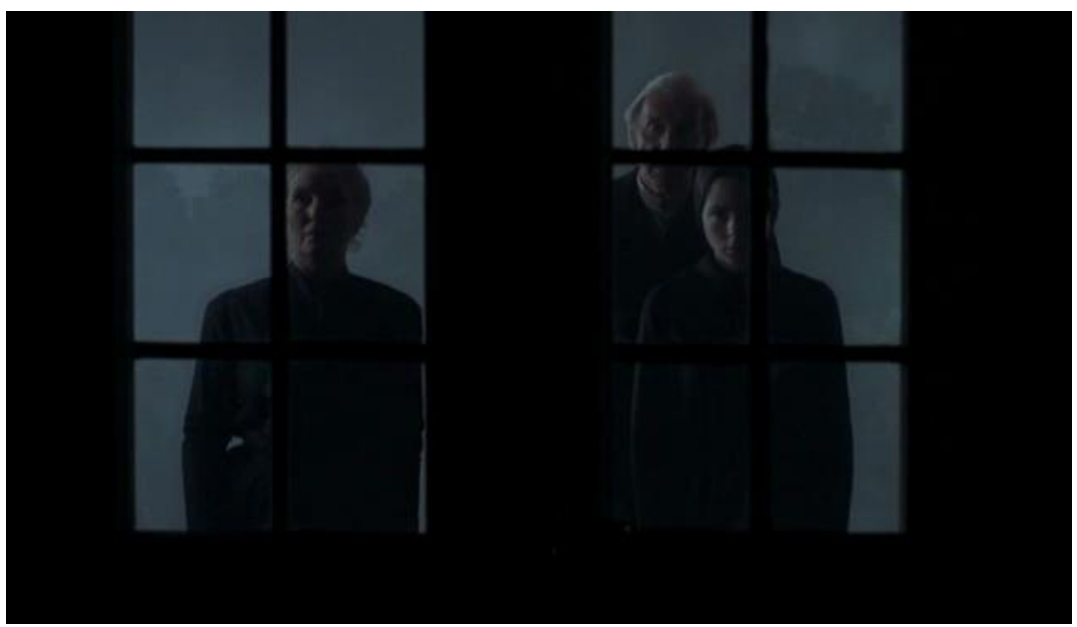


Imagen 11: Asunción de la culpa y la fantasmagoría

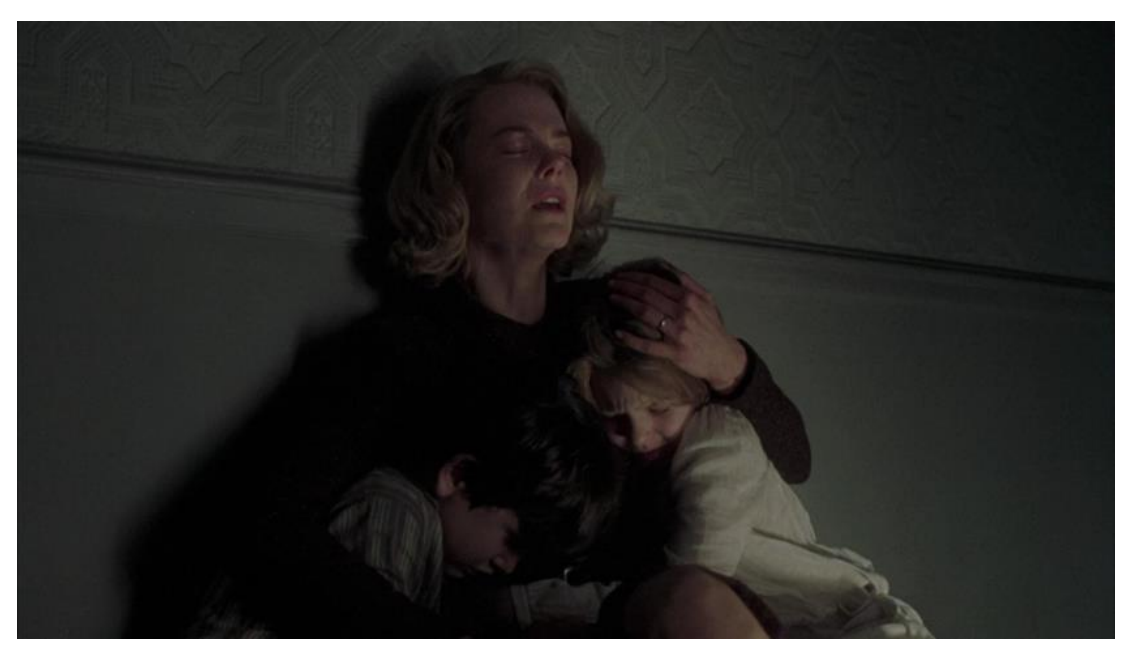

Imagen 12: Espectros residentes y residuales en la hipodiégesis del más allá

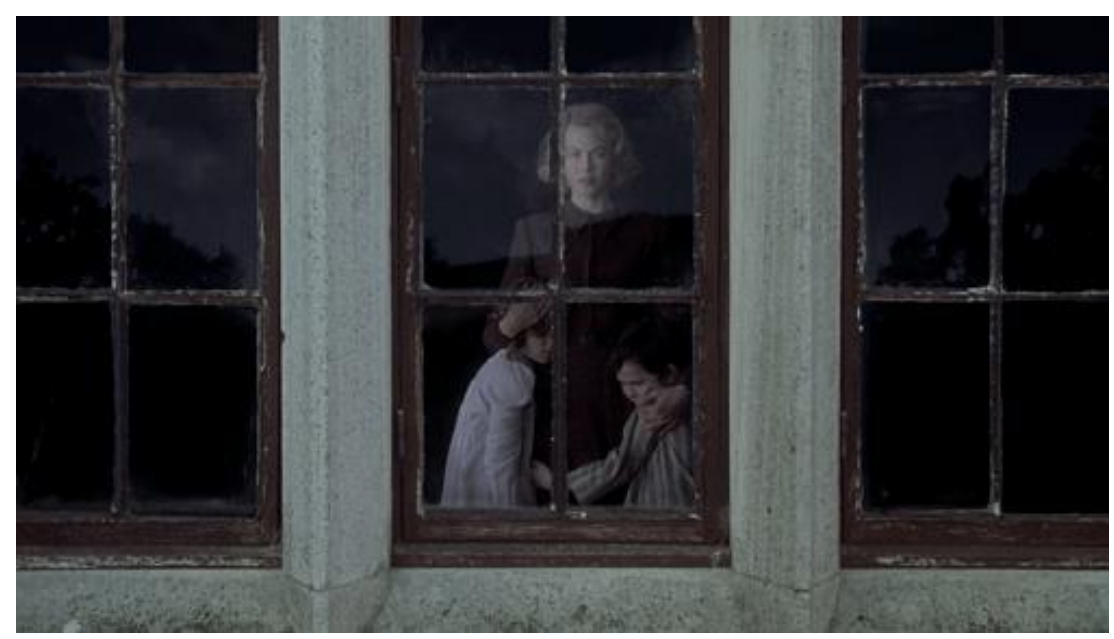

